\title{
A Preliminary Scoring Model to Predict In-hospital Mortality Risk for Geriatric Patients with Delirium
}

\author{
Nyoman Astika ${ }^{1}$, Dwijo Anargha Sindhughosa ${ }^{1 *} \mathbb{D}$, R. A. Tuty Kuswardhani ${ }^{1}$, Ida Bagus Amertha Putra Manuaba ${ }^{2,3}$ \\ ${ }^{1}$ Department of Internal Medicine, Faculty of Medicine, Universitas Udayana, Sanglah General Hospital, Denpasar, Bali, \\ Indonesia; ${ }^{2}$ Department of Medicine, College of Medicine, Taipei Medical University, Taipei, Taiwan; ${ }^{3}$ Medical and Health \\ Education Unit, Faculty of Medicine, Universitas Udayana, Denpasar, Bali, Indonesia
}

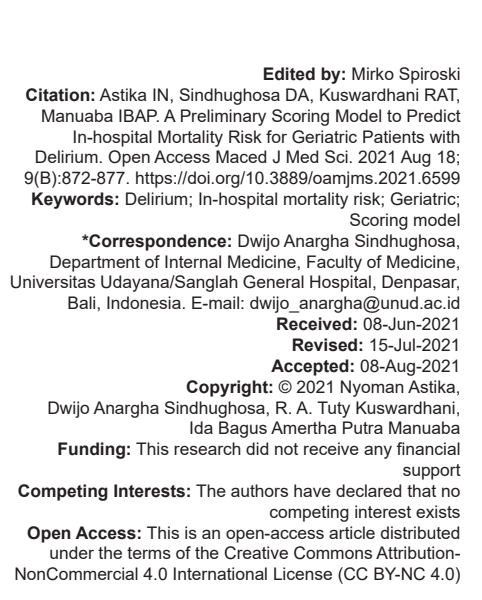

Abstract

BACKGROUND: Elderly patients are at an increased risk of death, particularly those with altered mental status.

AIM: We aimed to develop a scoring model from simple clinical data and routine laboratory testing to aid in predicting in-hospital mortality risk for geriatric patients with delirium.

METHODS: A total of 73 hospitalized geriatric patients with delirium were included in the study. A multivariate regression analysis employed to obtain independent risk factors to predict in-hospital mortality. All patients were followed until dead or discharged from hospital. The formula of (B/SE)/lowest B/SE was used to calculate the scores for each variable with strong discrimination power to be included in scoring system.

RESULTS: A total of $25(34.2 \%)$ of patients were death when being hospitalized. The mean age of the patients was $73.27 \pm 7.8$. From a total of 20 probable variables, three variables were then included in constructing the scoring model; no caregiver $(p<0.012)$, abnormal diastolic blood pressure $(p<0.05)$, and abnormal serum SGOT levels $(p<0.03)$. Each variable was scored as 1 , following the use of formula. Total score ranges from 0 to maximum of 3. The cutoff score of $\geq 2$ provided the best accuracy with sensitivity of $40 \%$ and specificity of $89.6 \%(p<0.001)$ The probability of in-hospital mortality was $8.8 \%, 32.6 \%, 70.8 \%$, and $92.4 \%$ for the total score of $0,1,2$, and 3 , respectively.

CONCLUSION: This novel scoring system with simple examination may aid to identify geriatric patients with delirium which possess higher risk for in-hospital mortality.

\section{Introduction}

Delirium is an acute neuropsychiatric condition which accounts for approximately $25 \%$ of people aged over 65 years old being hospitalized. It characterized by acute and fluctuated onset of attention disorders, consciousness, memory, arousal, orientation, and behavior along with disturbance in perception and sleep cycle. The etiology is complex and multifactorial, including infection, sleep deprivation, pain, specific organ disturbances, and metabolic alteration [1].

Delirium associated with increased risk of morbidity, mortality, and loss of independence [2]. The previous studies reported the association between delirium and mortality in the setting of hospital, although the obtained finding inconsistent. Study conducted by Dolan et al. [3] found that delirium is not associated with mortality after adjusted with confounding factors, but in contrast with Kakuma et al. [4], in which delirium associated with increased risk of mortality even after adjusted with confounding factors. If linked with mortality in hospitalized delirium patients, the index admission mortality rate is between $9 \%$ and $23.9 \%$ [5], [6].
A plentiful of study regarding delirium in hospitalized patients has been performed. Various serial cases and case-control study has reported the important predisposing and precipitating factors for the occurrence of delirium. The predisposing factors are very dependent to the setting. In the setting of medical wards, polypharmacy, use of psychoactive drugs, physical restraints, and renal impairment are main factors. A study by Magny et al. [7] found that infection in particular organs, neurological condition, and other acute diseases (heart failure, hypoglycemia, malignancy, etc.) are factors which may precipitate delirium.

From the existing literatures, it could be hypnotized that delirium could affect the risk of mortality among geriatric patients. However, there are still no existing literature which describe the development available scoring system to predict in-hospital mortality of delirium patients. One study has described the impact of delirium on in-hospital mortality risk in intensive care settings, and only adding delirium to currently available the Acute Physiology and Chronic Health Evaluation-II (APACHE-II) score, but not develop a new scoring system [8]. The precipitating factors of delirium included 
infection, electrolyte and metabolic alteration, and specific organ disturbances. Hence, using the simple and routine laboratory markers which indicate infection, metabolic disturbance, and specific organ disturbances, we aimed to predict the risk for in-hospital mortality of geriatric delirium patients.

\section{Methods}

\section{Population and study design}

This was a prospective cohort study involved 73 geriatric patients with delirium to predict the risk for in-hospital mortality of geriatric delirium patients. The study consisted of 34 male and 39 female patients. All geriatric patients ( $\geq 60$ years old) with delirium were included in this study. The diagnosis of delirium was set by the clinical and confirmed with Confusion Assessment Method (CAM). The sample obtained with consecutive sampling. Disease comorbidity (caregiver status, history of diseases, e.g. heart failure, hypertension, diabetes mellitus, and kidney failure) of the patients obtained from comprehensive interview. Physical examination performed to obtain systolic and diastolic blood pressure, pulse rate, and temperature of the patients. Routine laboratory tests which included in this study were white blood cells, hemoglobin, fasting blood glucose, aspartate aminotransferase (AST) level, albumin, blood urea nitrogen (BUN), creatinine, natrium, and $\mathrm{pH}$ of the artery. The exclusion criteria were patients with malignancy. This study has been approved by local ethical committee. All study participants, or their legal guardian, provided informed written consent before study enrollment.

\section{Demographic, clinical, and laboratory value of the study}

The variables included in this study were 20 variables, in which each variable classified into two classifications. Age classified into two categories, with cutoff of 73 (obtained from the mean age of the study). Caregiver status defined as whether the patients had any caregiver before admission. It was divided into no (without) caregiver and yes. Diseases comorbidity was classified into yes (with) or no (without) history of the diseases. Normal systolic blood pressure defined as $90-140 \mathrm{mmHg}$, while normal diastolic blood pressure defined as $60-90 \mathrm{mmHg}$. Normal pulse rate was $60-100$ times/min. The patients defined as fever if the axilla temperature was more than $37.5^{\circ} \mathrm{C}$ when admitted. Leukocytosis was defined as white blood cells $>11 \times 103 / \mu \mathrm{L}$ and anemia if the hemoglobin level $<10 \mathrm{~g} / \mathrm{dL}$. Normal fasting blood glucose was defined as 70-130. Abnormal AST defined as $>2$ times upper normal limit. Hypoalbuminemia defined if the albumin serum level $<3 \mathrm{~g} / \mathrm{dL}$, while high BUN level defined as $>23 \mathrm{mg} / \mathrm{dL}$. High serum creatinine defined as $>1.3 \mathrm{mg} /$ $\mathrm{dL}$ and normal natrium levels if the natrium serum was 136-145 mmol/L; normal artery $\mathrm{pH}$ defined as 7.35-7.4.

\section{Statistical analysis}

Statistical analysis was performed with Statistical Package for the Social Sciences version 23.0. Descriptive analysis was performed for all variables. Data with normal distribution presented as mean \pm standard deviation, while data without normal distribution presented as median (minimum-maximum value). Independent t-test and Mann-Whitney U-test were performed as appropriate. Bivariate analysis of categorical data was done with either Chi-square or Fisher's exact test. $p<0.05$ was considered statistically significant.

Multivariate analysis of regression logistic was performed for all 20 variables to obtain independent risk factors to predict in-hospital mortality in geriatric patients with delirium. The backward method was used for this analysis. All significant variables with strong discrimination power were included in final scoring system. The following formula was used to calculate the scores for each variable in scoring system: (B/SE)/ lowest B/SE. The quality of the scoring system obtained was analyzed with receiver operating characteristic (ROC) curves. To obtain the probability of in-hospital mortality, formula of: $1 / 1+\exp (-y)$ was used. The ROC curve performed to determine the optimal cutoff for the scoring system.

\section{Results}

A total of 73 geriatric patients in Sanglah General Hospital were included in this study. All patients were in delirium. Twenty-five patients (34.2\%) were death when being hospitalized. The mean age of the patients involved in this study was $73.27 \pm 7.8$. The demographic characteristics of the study samples are depicted in Table 1.

We identify the variables in which it may be related to the prognosis of the patients. The variables being included were disease comorbidity (history of diseases), physical examination, and routine laboratory examination (complete blood count, chemistry, electrolyte, and $\mathrm{pH}$ of the artery). A total of 20 variables were included in the study. Bivariate analysis was performed (Table 2). The variables of caregiver 
and pulse rate associated with in-hospital mortality ( $p=0.001$ and $p=0.005$, respectively).

Table 1: Demographic characteristics of study patients

\begin{tabular}{|c|c|c|c|}
\hline \multirow[t]{2}{*}{ Characteristics } & \multicolumn{2}{|l|}{ Patients' outcome } & \multirow[t]{2}{*}{$p$ value } \\
\hline & Dead $(n=25)$ & Alive $(n=48)$ & \\
\hline Age, years & $72.56 \pm 8.257$ & $73.65 \pm 7.561$ & $0.57^{\mathrm{a}}$ \\
\hline Systolic blood pressure, $\mathrm{mmHg}$ & $120(80-180)$ & $120(70-170)$ & $0.28^{\mathrm{b}}$ \\
\hline Diastolic blood pressure, $\mathrm{mmHg}$ & $70(50-100)$ & $80(40-100)$ & $0.05^{\mathrm{b}}$ \\
\hline Pulse rate, times/minutes & $110(77-129)$ & $90(76-120)$ & $0.01^{\mathrm{b}}$ \\
\hline Temperature, ${ }^{\circ} \mathrm{C}$ & $37.3(36.4-38.3)$ & $36.8(36-38.5)$ & $<0.01 \mathrm{~b}$ \\
\hline Leukocytes, $10^{3} / \mu \mathrm{L}$ & $12.7(6.89-22.64)$ & $11.65(5.41-879)$ & $0.19^{\mathrm{b}}$ \\
\hline Hemoglobin, g/dL & $11.77 \pm 1.97$ & $11.13 \pm 2.81$ & $0.32^{\mathrm{a}}$ \\
\hline AST, U/L & $28.5(7.7-419.7)$ & $23.6(6.6-209.6)$ & $0.20^{\mathrm{b}}$ \\
\hline Albumin, $\mathrm{g} / \mathrm{dL}$ & $3.4(1.5-4.7)$ & $3.4(1.7-32)$ & $0.98^{\mathrm{b}}$ \\
\hline BUN, mg/dL & $28.4(5.8-174)$ & $20.75(0.43-216.8)$ & $0.15^{\mathrm{b}}$ \\
\hline $\mathrm{SC}, \mathrm{mg} / \mathrm{dL}$ & $1.48(0.26-12.32)$ & $1.09(0.26-20.3)$ & $0.36^{\mathrm{b}}$ \\
\hline Fasting blood glucose, $\mathrm{mg} / \mathrm{dL}$ & $126(78-240)$ & $128(70-229)$ & $0.70^{\mathrm{b}}$ \\
\hline Blood pH & $7.4(7.01-7.53)$ & $7.42(7.11-7.61)$ & $0.24^{\mathrm{b}}$ \\
\hline Natrium, $\mathrm{mmol} / \mathrm{L}$ & $139(114-151)$ & $141(116-164)$ & $0.62^{\mathrm{b}}$ \\
\hline
\end{tabular}

AST: Aspartate aminotransfor BUN: Blood urea nitrogen SC: Serum creatinine, ${ }^{a} \mathrm{D}$ ata analyzed with

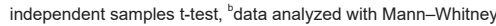

In the final model of the multivariate analysis with logistic regression, it was found that three variables out of a total of 20 variables included in the multivariate analysis were significant; without caregiver $(p=0.012)$, abnormal diastolic blood pressure $(p=0.05)$, and abnormal serum AST ( $p=0.03$ ) (Table 3 ). To determine its quality, the Hosmer and Lemeshow test was performed, depicting a significance of $>0.05$. The area under curve (AUC) of the final model showed the total of $82 \%$ ( $p<0.001$, Figure 1). Only the significant variables were included in the scoring system. Each variable was scored as 1 , following the use of formula: (B/SE)/lowest B/SE.

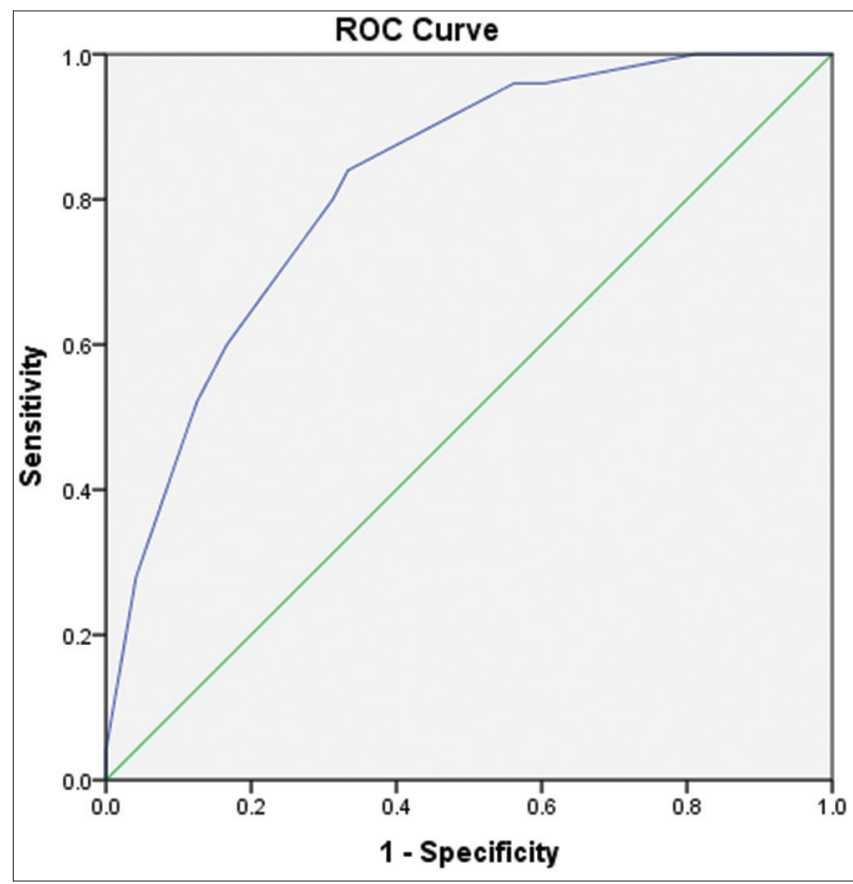

Figure 1: The ROC curve of the final model of multivariate analysis. (AUC: 0.82; $p$ < 0.001), ROC: Receiver operating characteristic, AUC: Area under curve

Total score ranges from 0 to maximum of 3 . The probability of in-hospital mortality was calculated with formula: $1 / 1+\exp (-y)$. The probability of in-hospital mortality was $8.8 \%, 32.6 \%, 70.8 \%$, and $92.4 \%$ for the total score of $0,1,2$, and 3 , respectively (Table 4 ). The cutoff score of $\geq 2$ provided the best
Table 2: Bivariate analysis of all potential variables in predicting in-hospital mortality

\begin{tabular}{|c|c|c|c|}
\hline \multirow[t]{2}{*}{ Characteristics } & \multicolumn{2}{|c|}{ Patients' outcome } & \multirow[t]{2}{*}{$p$ value } \\
\hline & Dead $(n=25)$ & Alive $(n=48)$ & \\
\hline \multicolumn{4}{|l|}{ Gender, n (\%) } \\
\hline Male & $14(41.2)$ & $20(58.8)$ & \multirow[t]{2}{*}{$0.24^{*}$} \\
\hline Female & $11(28.2)$ & $28(71.8)$ & \\
\hline \multicolumn{4}{|l|}{ Age } \\
\hline$>73$ & $11(30.6)$ & $25(69.4)$ & \multirow[t]{2}{*}{$0.51^{*}$} \\
\hline$\leq 73$ & $14(37.8)$ & $23(62.2)$ & \\
\hline \multicolumn{4}{|l|}{ Caregiver } \\
\hline No & $23(46.9)$ & $26(53.1)$ & \multirow[t]{2}{*}{$0.001^{*}$} \\
\hline Yes & $2(8.3)$ & $22(91.7)$ & \\
\hline \multicolumn{4}{|c|}{ History of heart failure } \\
\hline Yes & $8(57.1)$ & $6(42.9)$ & \multirow[t]{2}{*}{$0.06^{\star \star}$} \\
\hline No & $17(28.8)$ & $42(71.2)$ & \\
\hline \multicolumn{4}{|c|}{ History of hypertension } \\
\hline Yes & $14(42.4)$ & $19(57.6)$ & \multirow[t]{2}{*}{$0.18^{*}$} \\
\hline No & $11(27.5)$ & $29(72.5)$ & \\
\hline \multicolumn{4}{|c|}{ History of diabetes mellitus } \\
\hline Yes & $12(48)$ & $13(52)$ & \multirow[t]{2}{*}{$0.07^{*}$} \\
\hline No & $13(27.1)$ & 35 (72.9) & \\
\hline \multicolumn{4}{|c|}{ History of kidney failure } \\
\hline Yes & $10(52.6)$ & $9(47.4)$ & $0.05^{\star}$ \\
\hline No & $15(27.8)$ & $39(72.2)$ & \\
\hline Systolic blood $p$ & & & \\
\hline Abnormal & $8(44.4)$ & $10(55.6)$ & $0.29^{*}$ \\
\hline Normal & $17(30.9)$ & $38(69.1)$ & \\
\hline Diastolic blood p & & & \\
\hline Abnormal & 7 (63.6) & $4(36.4)$ & $0.04^{\star *}$ \\
\hline Normal & $18(29)$ & $44(71)$ & \\
\hline Pulse rate & & & \\
\hline Abnormal & $14(56)$ & $11(44)$ & $0.005^{*}$ \\
\hline Normal & $11(22.9)$ & $37(77.1)$ & \\
\hline Fever & & & \\
\hline Yes & $6(66.7)$ & $3(33.3)$ & $0.06^{\star \star}$ \\
\hline No & $19(29.7)$ & $45(70.3)$ & \\
\hline Leukocytosis & & & \\
\hline Yes & $18(40)$ & $27(60)$ & $0.19^{*}$ \\
\hline No & $7(25)$ & $21(75)$ & \\
\hline Anemia & & & \\
\hline Yes & $5(22.7)$ & $17(77.3)$ & $0.17^{*}$ \\
\hline No & $20(39.2)$ & $31(60.8)$ & \\
\hline Fasting blood gl & & & \\
\hline Abnormal & $11(36.7)$ & $19(63.3)$ & $0.72^{*}$ \\
\hline Normal & 14 (32.6) & $29(67.4)$ & \\
\hline AST serum leve & & & \\
\hline Abnormal & $5(55.6)$ & $4(44.4)$ & $0.26^{* \star}$ \\
\hline Normal & $20(31.3)$ & $44(68.8)$ & \\
\hline Hypoalbuminem & & & \\
\hline Yes & $5(27.8)$ & $13(72.2)$ & $0.51^{*}$ \\
\hline No & $20(36.4)$ & 35 (63.6) & \\
\hline BUN & & & \\
\hline High & $14(40)$ & $21(60)$ & $0.32^{*}$ \\
\hline Normal & $11(28.9)$ & 27 (71.1) & \\
\hline Serum creatinin & & & \\
\hline High & $15(40.5)$ & $22(59.5)$ & 0.25 \\
\hline Normal & $10(27.8)$ & 26 (72.2) & \\
\hline Natrium levels & & & \\
\hline Abnormal & $14(41.2)$ & $20(58.8)$ & $0.24^{*}$ \\
\hline Normal & $11(28.2)$ & $28(71.8)$ & \\
\hline $\mathrm{pH}$ of artery & & & \\
\hline Abnormal & 17 (39.5) & $26(60.5)$ & $0.25^{*}$ \\
\hline Normal & $8(26.7)$ & $22(73.3)$ & \\
\hline $\begin{array}{l}{ }^{*} \text { Chi-square, }{ }^{* *} \text { Fish } \\
\text { blood pressure: } 90 \\
\text { times/min, fever: }> \\
\text { (70-130), abnorma } \\
\text { high BUN: }>23 \mathrm{mg} / \\
\text { artery pH: } 7.35-7.4\end{array}$ & $\begin{array}{l}\text { te aminotransfera } \\
\text { stolic blood press } \\
1 \times 10^{3} / \mathrm{\mu L} \text {, anemi } \\
\text { ormal limit, hypoa } \\
\text { e: }>1.3 \mathrm{mg} / \mathrm{dL} \text {, no }\end{array}$ & $\begin{array}{l}\text { Blood urea nitrog } \\
0 \mathrm{mmHg} \text {, normal } \\
\text { dL, normal fasting } \\
\text { ia: Albumin serun } \\
\text { rium levels: } 136-1\end{array}$ & $\begin{array}{l}\text { al systolic } \\
\text { : 60-100 } \\
\text { g/dL, } \\
\text { L, normal }\end{array}$ \\
\hline
\end{tabular}

Table 3: Final model of multivariate analysis with logistic regression, from the total of 20 variables, along with its scoring points

\begin{tabular}{|c|c|c|c|c|c|c|c|}
\hline \multirow[t]{2}{*}{ Variables } & \multirow[t]{2}{*}{ B } & \multirow[t]{2}{*}{ SE } & \multirow[t]{2}{*}{$\operatorname{Exp}(B)$} & \multicolumn{2}{|c|}{$95 \% \mathrm{Cl}$} & \multirow[t]{2}{*}{$p$} & \multirow[t]{2}{*}{ Score } \\
\hline & & & & Lower & Upper & & \\
\hline Male gender & 1.183 & 0.631 & 3.263 & 0.948 & 11.233 & 0.061 & - \\
\hline Without care giver & 2.283 & 0.906 & 9.805 & 1.660 & 57.920 & $0.012^{*}$ & 1 \\
\hline $\begin{array}{l}\text { Abnormal diastolic blood } \\
\text { pressure }\end{array}$ & 1.607 & 0.832 & 4.987 & 0.976 & 25.474 & $0.050^{*}$ & 1 \\
\hline Fever & 1.401 & 0.872 & 4.058 & 0.735 & 22.421 & 0.108 & - \\
\hline Abnormal serum & 1.956 & 0.902 & 7.074 & 1207 & 41.456 & $0.030^{*}$ & \\
\hline
\end{tabular}

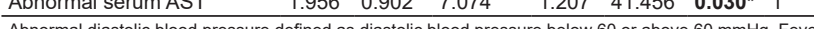
Abnormal diastolic blood pressure defined as diastolic blood pressure below 60 or above $60 \mathrm{mmHg}$. Fever defined as above $37.5^{\circ} \mathrm{C}$. Abnormal serum AST defined as AST level above $\times 2$ upper normal limit. *Only
significant variables were included in the scoring system. AST: Aspartate aminotransferase

accuracy with sensitivity of $40 \%$ and specificity of 89.6\% (AUC: 0.751; SE: 0.058; $p<0.001$; $95 \% \mathrm{Cl}$ : 0.637-0.864) (Figure 2). 
Table 4: Final model of the new scoring system to predict in-hospital mortality for geriatric patients with delirium (CODY SCORE)

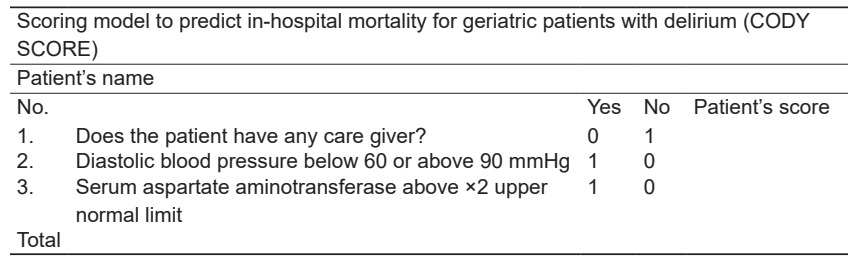

\begin{tabular}{lll}
\hline Interpretation & & \\
\hline & Total score & Probability for in-hospital mortality \\
\cline { 2 - 3 } Score 0-1: Low risk for & 0 & $8.8 \%$ \\
in-hospital mortality & 1 & $32.6 \%$ \\
Score 2-3: High risk & 2 & $70.8 \%$ \\
for in-hospital mortality & 3 & $92.4 \%$ \\
\hline
\end{tabular}

\section{Discussion}

Delirium is associated with prolonged hospitalization, increased mortality, and more likely discharge to a long-term care facility. Its impact on mortality has been examined in an advanced cancer population. A median survival of 21 days in delirious patients was compared with a median survival of 39 days in non-delirious patients. In the hypoactive subtype of delirium, the one most often overlooked, there was an increase in bedsores and infection. This is most likely related to the patients' relative immobility. There was an increase in mortality for the hypoactive subtype once admitted to a post-acute care unit [9], [10].

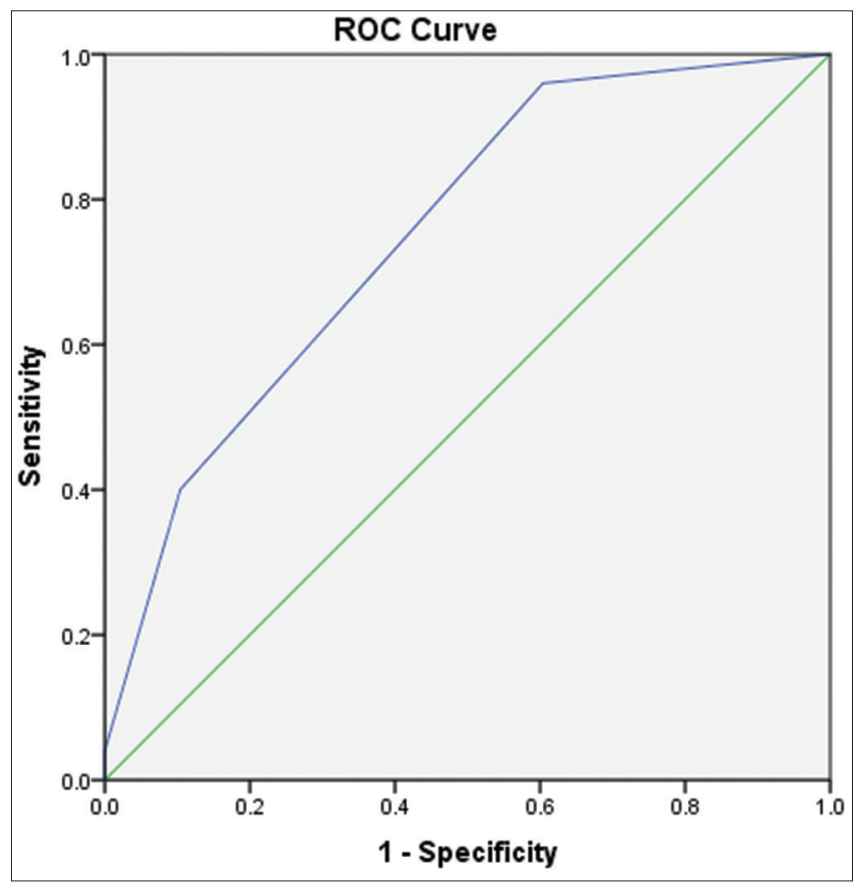

Figure 2: The ROC curve to determine the optimal cut-off for the scoring system. The cut-off score of $\geq 2$ provided the best accuracy with sensitivity of $40 \%$ and specificity of $89.6 \%$ (AUC: 0.751 ; SE: 0.058; $p$ < 0.001; 95\%Cl: 0.637-0.864). ROC: Receiver operating characteristic, AUC: Area under curve
In the current study, the results obtained found that among several variables ranging from demographic characteristics, comorbidities, vital signs, and several simple laboratory parameters which reflect inflammation and chemistry level, only caregiver status, blood pressure, and liver function test were significant as predictor of in-hospital mortality among the elderly with delirium.

To improve delirium recognition and care, numerous serum biomarkers have been investigated as potential tools for risk stratification, diagnosis, monitoring, and prognostication of delirium. Delirium is a common syndrome complex in systemic inflammatory states, including infections, cancer, and post-operative recovery. In the brain, inflammatory responses modulate neuronal functions such as neurotransmission and lead to a breakdown of the blood-brain barrier. Therefore, inflammatory markers may also be important biomarkers of delirium. The acutephase protein C-reactive protein (CRP) is a traditional marker of infection, inflammation, and tissue injury. Evidence has recently emerged of the relationship of CRP with neuroinflammatory processes. For instance, it is associated in the activation of vascular endothelial cells, a process that may explain the vulnerability of patients with organic brain disease to delirium caused by systemic inflammation [11], [12].

The neutrophil-to-lymphocyte ratio (NLR), which is a parameter derived from the differential white blood cell count, is a readily available marker of both inflammation and oxidative stress. It has recently been reported to be increased in elderly patients with delirium. The findings of study regarding NLR, white blood cells differential count, and CRP suggest that an inadequate response of the immune system and oxidative stress may play a role in the pathogenesis of delirium. Studies have shown that inflammatory markers and cytokines (i.e. neopterine and interleukin-8) can be detected in the cerebrospinal fluid of delirious patients. As previously mentioned, stress-induced physiological immune system response is defined by an increase in the neutrophil count and a concomitant decrease in the lymphocyte count. In delirium, elevated neutrophil count and NLR may reflect the degree of neuroinflammation and may be the basis of prediction of delirium by systemic inflammatory indicators. Lymphopenia and T-cell dysfunction are known predictors of mortality in ICU patients. Patients with lower lymphocyte levels showed a trend toward higher chance of coma and delirium, yet there was no significant relationship between lymphopenia and 30-day mortality [13]. In the current study, among several parameters which reflect inflammatory condition, no significant variables were observed to predict in-hospital mortality.

Comorbidity among people with dementia presents particular challenges for primary and secondary care. Certain comorbid medical conditions may exacerbate the progression of dementia. For 
example, cognitive decline may be accelerated in older people with type 2 diabetes. A qualitative study involving the views of 21 caregivers of people with dementia and type 2 diabetes found that behavioral and psychological symptoms of dementia disrupted diabetes care. Hepatic encephalopathy is a serious complication of acute and chronic liver disease that encompasses a continuum of neuropsychiatric abnormalities. It often leads to delirium in with poor prognostication in the elderly [14], [15]. In this study, we involved comorbidities of heart failure, hypertension, diabetes mellitus, and kidney failure in the analysis, although none were significant as predictor of in-hospital mortality.

The current study found that abnormal serum AST levels were significant as predictor of in-hospital mortality. Assays for gamma-glutamyltransferase (GGT), alanine aminotransferase (ALT), AST, and alkaline phosphatase (ALP) are the most common laboratory tests used for the detection of liver diseases. Several prospective epidemiological associations have been demonstrated between these markers of liver dysfunction and risk of type 2 diabetes mellitus, cardiovascular disease, or mortality from vascular and non-vascular causes in elderly peoples [14], [16]. Measurement of these liver enzymes, particularly assays for GGT and ALP, may serve as prognostic tools for the long-term prediction of mortality in clinical practice. They may also serve as screening tools to identify individuals at high risk of dying from all causes. Recent study from Kim et al. (2019) showed that larger changes (both increases and decreases) in the ALT, AST, and GGT levels over a 4-year period were associated with a higher risk of all-cause mortality when compared with smaller changes. In a study based on a representative US population data, lower baseline ALT levels were found to be associated with higher risks of cardiovascular disease, cancer, and liver disease mortality, whereas higher ALT levels were only associated with a higher risk of liver disease mortality. This finding concluded, the elderly with comorbid diseases in terminal state tends to have a change in level of function test, in which leads to mortality [17].

Caregivers play a key role in supporting the patient approaching end of life. Two domains of support for caregivers of people approaching end of life have been identified: (i) Support for the caregiver themselves and (ii) support for the caregiver to support the patient. National Institute for Health and Care Excellence clinical guidelines advocate the involvement of caregivers in the management of patients with delirium and recommend that information and support in relation to delirium should be offered to them [18]. The integrative review demonstrates the high level of distress and negative emotions experienced by families and caregivers of patients with delirium. Delirium also disrupts the relationship between the caregiver and the cared for person. High levels of emotional distress may be linked with the breakdown in the relationship with the patient, confusion, and lack of information about the causes and course of delirium, as well as helplessness in relation to how to support the patient [10], [18].

There are numerous diagnostic tools both for identification and severity assessment. Screening instruments are recommended for non-mental health professionals. Among the various screening and diagnostic instruments, CAM is commonly used for both screening and diagnosing delirium by non-mental health professionals. For rating of severity of delirium, Delirium Rating Scale-Revised-98 (DRS-R-98) has been the most commonly used scale in recent times. The DRS-R-98 total score is able to distinguish patients with delirium from those with other mental disorders such as dementia, schizophrenia, and depression during blind rating, with a sensitivity ranging from $91 \%$ to $100 \%$ depending on the cutoff score chosen. It is also the one of the most common scales used for evaluating the symptom profile or the phenomenology of delirium in various studies. Mini Mental Status Examination (MMSE) is also used for evaluating the cognitive impairment in patients with delirium. However, it is important to remember that MMSE can evaluate only the cognitive dysfunction [13], [19].

Several studies have described the importance of delirium in in-hospital mortality risk, however, none constructing a scoring system to predict in-hospital mortality risk of delirium patients. A study by van den Boogaard et al. evaluates whether delirium improves the predictive value of the APACHE-II score, in which the delirium occurs within $24 \mathrm{~h}$ after ICU admission. They found that delirium is a significant predictor of mortality and incorporating delirium as an additional variable to the APACHE-II model does not result in an improvement in its predictive estimates [8]. Another study by McCusker et al. also only found delirium as a marker for increased mortality during the 12 months after hospital admission in older medical inpatients [20]. Both studies did not develop a scoring system to predict in-hospital mortality.

This study provides new insight regarding the use of simple clinical and laboratory data in predicting in-hospital mortality risk. The current study provides proof that risk for in-hospital mortality among elderly patients with delirium could be calculated using interview, physical examination, and routine laboratory testing.

\section{Conclusion}

Among several routine physical and laboratory examination conducted in hospital, care giver status, blood pressure and AST levels may predict the in-hospital mortality risk in elderly delirium patients. This 
novel scoring system may benefit physician to predict the in-hospital mortality risk of this group of patients.

\section{Authors' Contributions}

INA designed the research, collect material and clinical data, and writing the manuscript; DAS designed the research, collect material and clinical data, analyzed the data, and writing the manuscript; RATK collect material and clinical data, analyzed the data, and revised the manuscript; and IBAMP designed the research, analyzed the data, and writing the manuscript. All authors read and approved the final manuscript.

\section{References}

1. Diwell RA, Davis DH, Vickerstaff V, Sampson EL. Key components of the delirium syndrome and mortality: Greater impact of acute change and disorganised thinking in a prospective cohort study. BMC Geriatr. 2018;18(1):24. https:// doi.org/10.1101/251272

PMid:29370764

2. Kiely DK, Marcantonio ER, Inouye SK, Shaffer ML, Bergmann MA, Yang FM, et al. Persistent delirium predicts greater mortality. J Am Geriatr Soc. 2009;57(1):55-61. https:// doi.org/10.1111/j.1532-5415.2008.02092.x

PMid:19170790

3. Dolan MM, Hawkes WG, Zimmerman SI, Morrison RS, GruberBaldini AL, Hebel JR, et al. Delirium on hospital admission in aged hip fracture patients: Prediction of mortality and 2-year functional outcomes. J Gerontol A Biol Sci Med Sci. 2000;55(9):M527-34. https://doi.org/10.1093/gerona/55.9.m527 PMid:10995051

4. Kakuma R, du Fort GG, Arsenault L, Perrault A Platt RW, Monette $\mathrm{J}$, et al. Delirium in older emergency department patients discharged home: Effect on survival. J Am Geriatr Soc. 2003;51(4):443-50. https://doi. org/10.1046/j.1532-5415.2003.51151.x

PMid:12657062

5. Inouye SK. The dilemma of delirium: Clinical and research controversies regarding diagnosis and evaluation of delirium in hospitalized elderly medical patients. Am J Med. 1994;97(3):27888. https://doi.org/10.1016/0002-9343(94)90011-6 PMid:8092177

6. Navinés R, Gómez E, Franco JG, de Pablo J. Delirium in a consultation liaison psychiatry unit of a general hospital. Actas Esp Psiquiatr. 2001;29(3):159-64. PMid: 11412490

7. Magny E, Le Petitcorps H, Pociumban M, Bouksani-Kacher Z, Pautas É, Belmin J, et al. Predisposing and precipitating factors for delirium in community-dwelling older adults admitted to hospital with this condition: A prospective case series. PLoS
One. 2018;13(2):e0193034. https://doi.org/10.1371/journal. pone. 0193034

PMid:29474380

8. van den Boogaard $M$, Peters $S A$, van der Hoeven JG, Dagnelie PC, Leffers P, Pickkers P, et al. The impact of delirium on the prediction of in-hospital mortality in intensive care patients. Crit Care. 2010;14(4):R146. https://doi.org/10.1186/cc9214 PMid:20682037

9. Avelino-Silva TJ, Campora F, Curiati JAE, Jacob-Filho W. Prognostic effects of delirium motor subtypes in hospitalized older adults: A prospective cohort study. PLoS One. 2018;13(1):e0191092. https://doi.org/10.1371/journal. pone.0191092

PMid:29381733

10. LeGrand SB. Delirium in palliative medicine: A review. J Pain Symptom Manage. 2012;44(4):583-94.

\section{PMid:22682074}

11. Xiang $\mathrm{D}$, Xing $\mathrm{H}$, Tai $\mathrm{H}$, Xie $\mathrm{G}$. Preoperative C-reactive protein as a risk factor for postoperative delirium in elderly patients undergoing laparoscopic surgery for colon carcinoma. Biomed Res Int. 2017;2017:5635640. https://doi. org/10.1155/2017/5635640

PMid:29181397

12. Chu C, Liang $\mathrm{C}$, Lin $\mathrm{Y}$, Chow $\mathrm{PC}$, Pan $\mathrm{C}$, Chou M, et al Biomarkers of delirium: Well evidenced or not? J Clin Gerontol Geriatr. 2011;2(4):100-4.

13. Kotfis K, Bott-Olejnik M, Szylińska A, Rotter I. Could neutrophilto-lymphocyte ratio (NLR) serve as a potential marker for delirium prediction in patients with acute ischemic stroke? a prospective observational study. J Clin Med. 2019;8(7):1075. https://doi.org/10.3390/jcm8071075

PMid:31336587

14. Suantio AM, Teh J, Sivasamy V, Wong AS, Lim SC. Hepatic encephalopathy masquerading as delirium. Acta Sci Neurol. 2018;1(1):18-24. https://doi.org/10.1186/s12916-014-0192-4

15. Bunn F, Burn AM, Goodman C, Rait G, Norton S, Robinson L, et al. Comorbidity and dementia: A scoping review of the literature. BMC Med. 2014;12:192.

16. Coggins CC, Curtiss CP. Assessment and management of delirium: A focus on hepatic encephalopathy. Palliat Support Care. 2013;11(4):341-52. PMid:23040331

17. Kim KN, Joo J, Sung HK, Kim CH, Kim H, Kwon YJ. Associations of serum liver enzyme levels and their changes over time with all-cause and cause-specific mortality in the general population: A large-scale national health screening cohort study. BMJ Open. 2019;9(5):e026965. https://doi.org/10.1136/ bmjopen-2018-026965 PMid:31154308

18. Finucane AM, Lugton J, Kennedy C, Spiller JA. The experiences of caregivers of patients with delirium, and their role in its management in palliative care settings: An integrative literature review. Psychooncology. 2017;26(3):291-300. https://doi. org/10.1002/pon.4140 PMid:27132588

19. Grover $S$, Avasthi A. Clinical practice guidelines for management of delirium in elderly. Indian J Psychiatry. 2018;60(3):S329-40. PMid:29535468

20. McCusker J, Cole M, Abrahamowicz M, Primeau F, Belzile E. Delirium predicts 12-month mortality. Arch Intern Med. 2002;162(4):457-63. https://doi.org/10.1001/archinte.162.4.457 PMid:11863480 